\title{
Phase II Trial of Diaziquone (AZQ) in Advanced Malignant Melanoma*
}

\author{
HERMAN HøST, $†$ RUDOLF JOSS, $\ddagger$ HERBERT PINEDO,§ UTA BRUNTSCH, $\|$ \\ FRANCO CAVALLI, ๆ GEORGETTE RENARD, ${ }^{* *}$ MARTINE VAN GLABBEKE** \\ and MARCEL ROZENCWEIG $\dagger+\ddagger \ddagger$
}

$\dagger$ Det Norske Radiumhospital, Montebello Oslo 3, Norway, łInstitut für Medizinische Onkologie, Inselspital, 3010 Bern, Switzerland, \$Academisch Ziekenhuis der Vrije Universiteit, De Boelelaan, 1117, 1081 HV Amsterdam, The Netherlands, $\| 5$ Medizinische Klinik, Klinik Nürnberg, Flurstrasse 15, 8500 Nürnberg, F.R.G., I Servizio de Oncologia, Ospedale San Giovanni, 6500 Bellinzona, Switzerland, **EORTC, Data Center, 1, rue Héger-Bordet, 1000 Brussels, Belgium and $\dagger \dagger$ Service de Médecine et Laboratoire d'Investigation Clinique H.J. Tagnon, Institut Jules Bordet, 1, rue Héger-Bordet, 1000 Brussels, Belgium

\begin{abstract}
Forty-two evaluable patients with malignant melanoma received $A Z Q$ $27 \mathrm{mg} / \mathrm{m}^{2}$ i.v. every 4 weeks. In 5 patients with poor marrow reserve this dose was reduced to $20 \mathrm{mg} / \mathrm{m}^{2}$. Doses were rapidly escalated when no significant myelosuppression was encountered in previous courses. Twenty-five patients had received no prior chemotherapy. A single partial response was obtained for 3 months. Inconsistent myelosuppression was the main toxic effect in this trial. The median WBC and platelet nadirs were $3200 / \mathrm{mm}^{3}(900-19,500)$ and $105,000 / \mathrm{mm}^{3}$ (33,000-530,000) respectively. In 2 patients leukopenia was complicated by a transient episode of infection. One-third of the patients did not experience significant myelosuppression. Non-hematologic adverse reactions were generally mild to moderate and consisted of nausea and vomiting in 26 patients and alopecia in 1 . It is concluded that at this dose schedule AZQ is ineffective against malignant melanoma.
\end{abstract}

\section{INTRODUCTION}

AZIRIDINYLBENZOQUINONES appear to be compounds with potential value for the treatment of malignancies in the central nervous system $[1,2]$. These drugs possess physicochemical properties which enable them to penetrate the central nervous system, i.e. they are small lipophilic

Accepted 9 November 1982.

Other participants in this study: Edward Newlands (Charing Cross Hospital, London, U.K.), Vivien Bramwell (Christie Hospital, Manchester, U.K.), Wim ten Bokkel Huinink (Netherland Cancer Institute, Amsterdam, The Netherlands), Pierre Siegenthaler (Hôpital des Cadolles, Neuchatel, Switzerland), Paul Obrecht (Kantonsspital, Basel, Switzerland) and Eduard Holdener (Kantonsspital, St Gallen, Switzerland).

* This work was supported in part by contract NIH N01 CM 53840 from the National Cancer Institute (NCI, Bethesda, MD), and carried out on behalf of the EORTC Early Clinical Trial-Group.

$\ddagger \ddagger$ Reprint requests and correspondence: Marcel Rozencweig, MD.. Head, Investigational Drug Section, Institut Jules Border, 1, rue Héger-Bordet, B-1000 Brussels (Belgium). molecules without ionic charge. AZQ [1,4cyclohexadienel,4-dicarbamic acid,2,5-bis(1-aziridinyl)-3,6-dioxodiethyl ester] (NSC-182986) was found to be the most promising compound for clinical trials among 31 aziridinylbenzoquinones [3].

AZQ is active against L1210 leukemia, P388 leukemia, B16 melanoma, colon 26, CD8F1 mammary tumor, human mammary tumor xenograft $\mathrm{MXl}$ and human colon tumor xenograft CX-2 [4]. It is of particular interest that AZQ is also active against intracerebrally implanted tumors, including the L1210 leukemia and ependymoblastoma. There is no apparent schedule dependency with respect to the activity of AZQ against L1210 [4] and its toxicity in large animals [5]. The mechanism of action of AZQ is not yet fully understood. It appears to cross-link DNA [6] and to produce free radicals [7]. Pharmacokinetic studies showed that the drug entered the cerebrospinal fluid in animals [8] and in humans [9-11].

Phase II results have been promising in malignant gliomas $[12,13]$ and have been less 